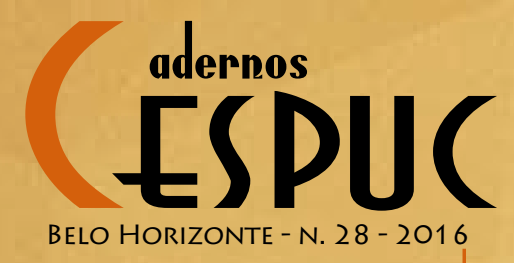

\title{
AS FAVAS DESCONTADAS POR LADISLAU EM "INTRUGE-SE"
}

Universidade de São Paulo - USP. Pós-doutoranda. Este artigo é realizado com financiamento da FAPESP como parte de uma pesquisa sobre "A inscrição do nome do autor na ordem ficcional de Tutaméia”, sob a supervisão do Prof. Dr. João Adolfo Hansen.

Maryllu de Oliveira Caixeta

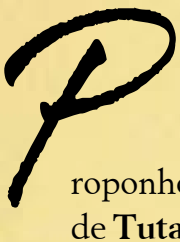
Trata-se de uma paródia de conto policial ambientado no sertão e protagonizado por vaqueiros que traziam uma boiada do Saririnhém quando se deparam com um crime. O protagonista não é um policial, mas o capataz Ladislau, que se encarrega de descobrir qual dos vaqueiros teria esfaqueado Quio. O conto recusa atender qualquer expectativa de um método ou de um raciocínio dedutivo que costumam ser os pontos fortes de um investigador, como nos contos realizados e teorizados por Edgar Allan Poe; e essa distorção faz o sentido da narração deslizar do investigador para a alegoria do autor que assinala o caráter cindido do sujeito e questiona o prestígio dado a ele nas sociedades modernas. A paródia do conto policial em "Intruge-se" integra um conjunto de contos de Tutaméia que propõem uma alegoria do autor. Esse artigo elaborará uma análise da paródia e da alegoria no conto de Rosa segundo a recusa da transparência da linguagem da qual trata Barthes com base na afirmação freudiana de que o caráter cindido do sujeito correlaciona-se à dualidade do signo. A investigação desarrazoada de Ladislau encena a perspectiva do autor que recusa padrões de representação realista como os utilizados no conto policial. $\mathrm{O}$ autor avalia o gênero conto como interferência no conto policial e aproxima-o da estória ou de uma invenção cujo valor consiste em intervir nas convenções narrativas para liberar a produção de sentido.

Palavras-chave: Guimarães Rosa. Tutaméia. Intruge-se. Autor.

O conto "Intruge-se" parodia o conto policial ao narrar a investigação de um caso de assassinato cuja solução deve-se a um acontecimento instantâneo e antilógico, puramente inventivo, que funciona como enigma insolúvel na alegoria que desfaz os 
liames na trama da estória. A estória difere do conto policial que espalha pistas para o leitor atar no final, quando desvenda a lógica do enredo, quando recompõe o alinhamento dado pelo autor à diversidade dos acontecimentos narrados. O leitor do conto policial compartilha com o autor uma concatenação de ideias, um argumento, uma verossimilhança. Com essa paródia poética, inventiva, do conto policial, "Intruge-se" recusa a justificação lógica do enredo verossímil e dilui alguns pontos de articulação na representação de um enigma sem solução. $\mathrm{O}$ narrador é empático a Ladislau, o capataz que se encarrega do caso agindo como uma espécie de mestre zen que combina um esforço de atenção extrema ao presente e abertura ao devir; esse gesto recusa a atitude típica do investigador em um conto policial que seria interrogar os suspeitos para deduzir uma lógica implícita nos encadeamentos dos eventos conhecidos por ele. $\mathrm{O}$ investigador do conto policial atua como quem segue um fio para chegar à meada. De modo diverso, Ladislau considera o estilo dos vaqueiros, como quando toca a mão deles e menciona a autoridade maior de Seo Drães, estilo que informa a qualidade da participação de cada um na trama do mundo ficcional. Com o gesto de tocar a mão dos vaqueiros, Ladislau lembra-os que, além de chefiar o grupo no pastoreio, a função de capataz encarrega-o de prestar contas a Seo Drães, do assassinato de Quio. Ladislau incomoda Liocádio ao tocar a mão dele e lembrá-lo da autoridade implicada nas funções, dos riscos implicados nas decisões cabíveis aos vaqueiros na condução do gado pelos caminhos mais ou menos abertos no sertão. Os vaqueiros metaforizam os profissionais liberais que trabalham a língua, que pode fomentar o pensamento e produzir ideologia; pastoreiam a linguagem que o gado rumina.

O substantivo feminino "mão" deriva do latim manus,us' que designa um membro situado na extremidade do corpo, que articula-se ao antebraço pelo punho e que termina pelos dedos. Do significado literal deriva o sentido figurado de autoridade, poder, estilo e os usos simbólicos regionalistas: maneira, envolvimento, participação, domínio, poder decisório, controle, cuidado (HOUAISS; VILLAR, 2009). Ladislau considera o estilo dos vaqueiros enquanto mantém os cuidados de capataz que não adia, prestimoso. Quando acharam Quio esfaqueado, Ladislau rezou pela alma do morto sem descer do cavalo, "antes de contar o gado". Nem mesmo foi Ladislau quem deu o veredito final, mas o velho vaqueiro Rigriz decidiu que Liocadio era o assassino logo depois que, no momento oportuno, o capataz atirou nele em defesa própria. O velho Rigriz, "homem 
de perita sensatez" ou de saber prático, é o único que não tem a mão tocada por Ladislau; Ladislau outorga o estilo provado, funcional, e interage com ele mais como ponderador do movimento do sentido do que como decifrador de enredos (ROSA, 1979, p.70 e 71). O culpado do assassinato de Quio ficou sendo Liocadio, que reagira sacando a faca depois de um segundo toque de Ladislau na mão dele. O estilo pressupõe uma avaliação e um modo refletido de articular os fragmentos selecionados no entorno; como a mão ligada à parte superior do corpo que encarregamos dos gestos de maior destreza, em silêncio de desempenho.

O conto apresenta uma alegoria do autor na qual os nomes encenam funções de signos motivados, cujos significantes reverberam significações equívocas na ficção da forma graças à mediação do autor que acumula semelhanças sonoras e etimologias fictícias. $\mathrm{O}$ estilo do autor produz indeterminações na forma, destina-a à reflexão do leitor e recusa a transparência da língua, que pressupõe a unidade do sujeito reduzido à consciência, diferenciando-a de um veículo transmissor de conteúdos. De acordo com Barthes, nos Fragmentos de um discurso amoroso, o texto moderno implementa um jogo do significante que faz deslizar as convenções narrativas - autor, representação, obra, enredo, alegoria, etc. - e dá energia ao leitor que precisa caber no jogo do significante, sonhar, praticar o trocadilho usufruindo os equívocos ou mover-se com força e ligeireza sobre a areia movediça da língua transparente que constitui o Imaginário.

(O sujeito que está sob o domínio do Imaginário 'não cabe' no jogo do significante: ele sonha pouco, não pratica o trocadilho. Se ele escreve, sua escritura é lisa como uma Imagem, ela quer sempre restaurar uma superfície lisível das palavras: anacrônica, em suma, em relação ao texto moderno - que, a contrario, se definiria a si mesmo pela supressão do Imaginário: nada de romance, nada de Imagem simulada: pois a Imitação, a Representação, a Analogia são formas da coalescência: fora de moda.) (BARTHES, 1984, p.75)

O texto moderno trabalha as convenções narrativas para o leitor usufruir delas como de uma moda cujo efeito de intensidade nega o fundamento transcendente dos gêneros; a força ou a energia desse efeito faz emergir do imaginário do leitor uma movimentação significante. 
Podemos desmembrar o nome do culpado, Liocadio, em "lio" e "cadio". O substantivo masculino "lio" designa aquilo que lia ou liga, um liame, e deriva do verbo transitivo flamengo liar que significa enrolar, amarrar e provocar. A pronúncia que um espanhol daria ao substantivo masculino "cadio" tem uma semelhança sonora com o substantivo masculino "cadilho" que designa os nós que dão acabamento às pontas das tramas tecidas no tear. "Cadilho" deriva do latim catellus, $i$ que também é diminutivo do latim catulus: designação carinhosa de um pequeno cachorro (HOUAISS; VILLAR, 2009). Liocadio é aquele que entrelaça os encadeamentos, aquele que enreda, trama, e personifica a ligação afetiva com o cachorrinho. Em "Intruge-se", um cachorrinho funciona como metáfora avaliativa da narração pelo autor. Antes de retomar a relação de Liocadio com o cão, vamos abrir um parêntese para considerar o ponto de vista de um cão, filósofo cínico (gr. kovikóৎ e lat. cynicus), sobre a picaresca no despontar da narração moderna.

No "Colóquio dos cães" das Novelas exemplares, Cervantes (2013) estilizou a novela picaresca e colocou o gênero em questão dando uma contribuição significativa na constituição da narração moderna que apresenta um estilo, uma perspectiva particular quanto ao mundo e quanto aos modos de narrar o mundo. Os cães comentam a narração e o narrador Berganza lamenta as dificuldades que tem em ser discreto $^{1}$ ou subordinar-

$1 \mathrm{O}$ advento da modernidade colocou em questão o lugar do indivíduo na condição, cada vez mais complexa, da prática discreta. No A arte da prudência, Baltasar Gracián faz algumas considerações sobre o valor do discreto, aquele que sabe atuar com prudência e perspicácia, sem incorrer no voluntarismo do Homem Novo. Cito apenas um exemplo. "Saber ajudar-se. Não há melhor companhia nas grandes aflições que um bom coração, que, quando fraquejar, haverá de ser suprido pelas partes que lhe estão próximas. São menores os afãs de quem se sabe valer. Não se renda ao destino, pois ele acabaria por ser intolerável. Alguns se ajudam pouco em seus trabalhos e dobram-nos por não saberem leva-los. Quem já se conhece socorre a fraqueza com a reflexão, e o discreto sai de tudo vitorioso, até das estrelas." (GRACIÁN, 2009, p.107) Saber ajudar-se com uma prática discreta tornou-se mais complexo depois que Freud apontou a contribuição do inconsciente na formação da consciência; a noção clássica de destino deu lugar à consideração do papel da consciência e do inconsciente na sensibilidade simbólica. se a um estado de coisas cuja simbologia falida a Espanha ainda ostentava; promete morder a própria língua mas continua avaliando o que narra, de um ponto de vista particular e precário, ao cínico Cipião. Cervantes estilizou estruturas da picaresca, como o personagem andarilho que serve a vários amos e faz a crítica de seu tempo, e, segundo Weimann, acrescentou complexidade à representação cujo sentido deriva da relação do ponto de vista do autor com o de um outro diverso, o narrador protagonista (WEIMANN, 1984, p.254 e 264). Na picaresca, a expressão relativamente direta do ponto de vista do autor por meio do narrador empático ao herói correspondia à psicologia burguesa, em formação na época, que evita a reflexão e valoriza o prazer, a repleção, reforçando a imersão do ego no imaginário. Cervantes avaliou a picaresca ao liberar a fala e um ponto de vista crítico aos cães que decidem usá-la para falar de si mesmos, das próprias memórias e experiências, em vez de perder tempo pensando em convenções narrativas arbitrárias. Berganza reivindica uma narração mais realista ao se queixar da diferença entre os pastores que conheceu e aqueles mencionados nos livros que a ama lia para um dos donos dele e 
que descreviam cenas arcádicas. O cínico Cipião faz a crítica ao narrador Berganza enquanto dialogam em baixo de uma janela do Hospital da Ressureição em Valladolid. O colóquio começa com eles admirados com o fato novo de que podem falar graças a um feitiço de Montiela.

[CIPIÓN] - Pero, sea lo que fuere, nosotros hablamos,
sea portento o no; que lo que el cielo tiene ordenado
que suceda, no hay diligencia ni sabiduria humana que
lo pueda prevenir; y así, no hay para qué ponermos a
disputar nosotros como o por qué hablamos; mejor será
que este buen día, o buena noche, la metamos en nuestra
casa; y, pues la tenemos tan buena en estas esteras y no
sabemos cuánto durará esta nuestra ventura, sepamos
aprovecharnos dela y hablemos toda esta noche, sin dar
lugar al sueño que nos impida este gusto, de mí por
largos tempos deseado. (CERVANTES, 2013, p.10, 12
e 26)

Os cães maravilham-se com as novas possibilidades de uma fala particular até então inacessível a eles que, tendo acumulado assunto e temor de coerção, avaliam o sono e o sonho de um ponto de vista clássico afastando-os como empecilhos.

O cão de "Intruge-se" chama-se Eu-Meu. "Ladislau tateava as patas do Eu-Meu, com ver que se muito gastadas." (ROSA, 1979, p.11) Se as convenções ensinam a dizer, também funcionam como interdições da fala particular que alimentam a curiosidade, motivam peregrinações como as do narrador tradicional e as narrações mais realistas fundadas na concepção de que o saber, limitado ou censurado pelas convenções, ocorre quando nos inteiramos de fatos encobertos ou inacessíveis e quando podemos dizê-los explicitamente. Na perspectiva do narrador andarilho e de seus ouvintes, não saber é estar alienado das coisas de interesse que estão sob o domínio de outros. De modo diverso, a concepção moderna de arte interessa-se pelo nada e explora os sons das palavras como origens lúdicas do sentido. O prefácio "Aletria e hermenêutica" cita uma anedota de Manuel Bandeira em Andorinha, Andorinha que relativiza a loucura poética de ouvir o nada, do louquinho no Hospício de Alienados que cola o ouvido à parede silenciosa por cinco horas, atribuindo a ela uma profecia ou uma antecipação das descobertas científicas acerca dos fenômenos sonoros.

Afinal de contas, a parede são vertiginosos átomos, soem ser. Houve já até, não sei onde ou nos EstadosUnidos, uma certa parede que irradiava, ou emitia por 


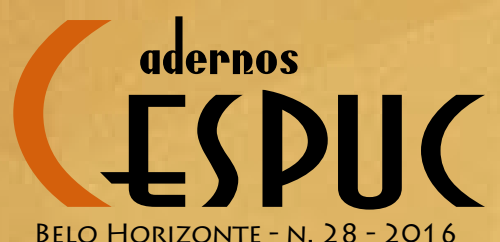

BELO HORIZONTE - N. $28-2016$ marullu de Oliveira (aixeta

si ondas de sons, perturbando os rádio-ouvintes etc. $\mathrm{O}$ universo é cheio de silêncios bulhentos. O maluquinho podia tanto ser um cientista amador quanto um profeta aguardando se completasse séria revelação. Apenas, nós é que estamos acostumados com que as paredes é que tenham ouvidos, e não os maluquinhos. (ROSA, 1979, p.11) [grifos do autor]

Metáfora da poesia, o maluquinho está encerrado no Hospício dos Alienados, privado daquilo que os narradores de conto costumam valorizar: argumento, aventura ou experiência civil da subjetividade, informação, repleção, brevidade, etc. Em "Intruge-se", mesmo quando os vaqueiros encontraram Quio assassinado, enquanto preparavam a cova e improvisavam uma cruz de dois paus nobres de sipipira, Eu-Meu chamavaos para continuar a viagem. "Eu-Meu latia para o pessoal e para a estrada." (ROSA, 1979, p.70) Ladislau não quis ver o esfaqueado, um dos da comitiva, por quem rezou sem descer do cavalo antes de contar o gado. A consideração das convenções no trabalho do estilo não deixa lugar para a indulgência e requer de Ladislau, uma das personas do autor, uma perspectiva ampla do funcionamento da comitiva, do cuidado com o gado. Embora ambos não tenham se ocupado muito do morto Quio, a perspectiva de Ladislau não se confunde com a de Eu-Meu: ansioso pela estrada, seriamente interessado na comida, capaz de aceitar agrados do assassino Liocádio e de nem latir na ocasião do esfaqueamento de Quio, como observou o velho Rigriz. O narcisismo humano é afetado pelo lugar deslocado que a paródia do conto policial dá à persona do autor e aos pronomes Eu-Meu que nomeiam o cachorro acompanhante do capataz Ladislau. Eu-Meu acordava Ladislau "a horas certas, sem latir nem rosnar, só com a presença” (ROSA, 1979, p.70). A metáfora zoomórfica de Eu-Meu diz respeito à apreciação que o autor faz do sujeito deslocado à função de presença falha e séria no auxílio que presta como companhia alerta, "cachorro grande, amarelo” como as ideias (ROSA, 1979, p.70).

Liocádio, que personifica o enredo, esfaqueou pelas costas Quio, que, encarado como elemento de composição, espanhola o som do morfema -quilo derivado do grego Kheílos, eos-ous e que significa lábio: contorno do órgão boca, sulco (HOUAISS; VILLAR, 2009). Quio dá significação trágica ao monologismo moderno resultante da cisão do colóquio, da extinção do colo, que significa habitar e cultivar: uma terra, amigos ou hábitos $(\text { colo })^{2}$; uma eloquência (loqui) ${ }^{3}$ acompanhada do prefixo (co). O latim colo vem do grego Kwelo, que significa circular, mover- 
se em volta; como no substantivo masculino bou-kólos que designa aquele que se move em volta dos bois cuidando deles, um boiadeiro, um vaqueiro (BOSI, 1993, p.11; MAGNE apud BOSI, 1993, p.385). Io, transformada em vaca como castigo por seduzir Júpiter, correu o mundo dando nome aos lugares onde passava, como o mar Jônico, até livrar-se do feitiço nas margens do Nilo (BULFINCH, 2006, p.39-41). A alegoria define Quio como metáfora da monologia que, segundo Bakhtin (1981), regula a cultura moderna desde o Renascimento a partir de quando o racionalismo europeu se fortaleceu e se propagou. O romance monológico reflete as opiniões ou a consciência do autor que a representa em unidades semânticas bem acabadas. A prosa ficcional desenvolveu-se até chegar à polifonia, que culmina em Dostoiévski e que tem origem numa vertente da carnavalesca, a sátira menipéia, que inclui o "Colóquio dos cães"(BAKHTIN, 1981, p.68).

O interesse de Guimarães Rosa por neologismos, além de poético, aponta o valor do significante nos processos cognitivos, que interessaram um pensador como Freud (1996) como quando escreveu sobre o chiste, e a Lacan (2005) no modo como concebe o real. A propósito da contribuição do criador da psicanálise, o estudo As razões do Iluminismo enfatiza que Freud tirou o sujeito da posição central que ele ocupava desde o iluminismo, que legou à razão ou à consciência a função de senhorio do mundo a ser dominado pelo homem. Freud concluiu que a consciência é apenas a superfície de processos internos eficientes e reprimidos, inconscientes (ROUANET, 1987, p.12 e 86). Segundo o Dicionário de psicanálise, o criador da psicanálise aprendeu espanhol lendo literatura, tinha predileção por Cervantes e passou dez anos assinando Cipião nas cartas que enviava a um amigo da adolescência que assinava Berganza (ROUDINESCO; PION, 1998, p. 712714). O método psicanalítico trata os pacientes pela fala que eles dirigem ao analista disposto a ouvir sem censurar e a atuar como um mediador do inconsciente acessado numa fala feita de associações livres. A propósito de Lacan, o dicionário informa que o psicanalista considerava a mediação do significante no registro da língua comparável à mediação do inconsciente na formação da consciência (ROUDINESCO; PION, 1998, p. 645 e 709). Tanto sob as formações da consciência como entre ela e nossos processos internos há lacunas através das quais emergem fenômenos linguísticos como os chistes, que incluem os neologismos, e as fantasias. O significante participa de um processo produtor de significação, que acaba por determinar o 
significado, e é essa função simbólica que constitui o homem. O estilo alegórico de Rosa tem base significante que recorre muito aos chistes, como quando propõe neologismos, quando acopla unidades de significação também nos nomes dos personagens e quando espalha pistas morfológicas para associações livres que ativam processos de significação.

Rosa usa a alegoria como recusa do monologismo e faz o sentido circular em torno dos vaqueiros de "Intruge-se", que funcionam como metáforas avaliativas da funcionalidade da invenção narrativa. A fantasia do autor mitifica situações que, quando relacionadas a dados biográficos sobre o nascimento do escritor, compõem uma alegoria da origem equívoca. Vera Novis (1989) informa que os pais de Rosa tiveram opiniões diversas sobre o nome que dariam ao filho. Como ele nasceu no dia de São Ladislau, o esperado seria nomeá-lo com o nome do santo que se convencionou comemorar naquela data e que foi o mais amado dos reis húngaros. Em todo caso, a vontade da mãe prevaleceu sobre a convenção e deram ao filho o nome João a despeito de São João ter sido comemorado três dias antes. O primeiro nome de João Guimarães Rosa tem origem numa escolha arbitrária ou numa vontade da mãe. João é aquele que inventa, enquanto Ladislau é aquele que deveria ter sido o nome ou o reconhecimento da participação do nome na cultura, a consciência crítica quanto ao caráter público do discurso. Como um rei justo e amado pelo povo, o outro do autor é aquele que considera as convenções: os usos históricos das palavras dicionarizadas, a morfologia nos neologismos, os usos históricos dos gêneros ou das categorias textuais literatura, autor, livro, forma, representação, invenção, estória, enredo, etc. Segundo Vera Novis (1989, p.56), Ladislau circula pelo universo ficcional de Tutaméia como personagem de três contos ("Intruge-se", "Vida ensinada" e "Zingaresca") e como narrador implícito em "O outro ou o outro". Ele é encarregado de guiar o grupo de vaqueiros que leva a boiada de Seo Drães que é apenas nomeado e referido como o maior fazendeiro do sertão, honrado por todos. O suposto método de Ladislau consistiu em tocar no assunto da compra da fazenda da Gralha por Seo Drães à medida que lançava no chão, uma a uma, as favas correspondentes aos vaqueiros da comitiva. Como se a investigação estivesse destinada ao êxito; uma questão de favas contadas ou de solução inevitável, algo já estabelecido, convencionado; Ladislau apenas não desempenhou o papel do agente principal da solução, ele coopera numa lógica discursiva que o transcende. A segurança de Ladislau contrasta com a 
inconsistência do método de lançar fora as favas até não restar nenhuma e, aparentemente evitando o assunto do assassinato, apenas mencionar a cada vaqueiro em particular a compra da fazenda Gralha por Seo Drães.

No artigo “The logic of paradox in Guimarães Rosa's Tutaméia”, Avelar (1994) afirma que as estórias de Tutaméia narram eventos contingentes e instantâneos nos quais personagens residuais não atuam como sujeitos nem como o avesso ou a falta do sujeito. A cena é dominada pelos eventos e os personagens são elementos, entre outros, na composição dela. Apenas as estórias dão relevo a acontecimentos dos quais os personagens não ocupam o centro de direção. Os personagens de Tutaméia não chegam a sofrer um efeito cabal da situação na qual atuam, não são formas de um fundo; também não podemos dizer que esses personagens atuam de modo independente das situações que, na verdade, os limitam estreitamente até que algum evento imprevisto transforma a situação-limite, desfavorável, inicial ou dá a ela uma significação redentora. "As paradoxical subjects, they dwell in the realm of pure becoming." Como no conto "Intruge-se", que é uma "anti-detective story" (AVELAR, 1994, p.76 e 77), Ladislau não resolve o mistério do crime, mas, em defesa própria, atira em Liocádio, que o velho vaqueiro Rigriz, "homem de perita sensatez", identifica como o assassino "por algum trato ou furto!", por razão indefinida (ROSA, 1979, p.71 e 73).

Rosa usa a língua operando indeterminações na forma que deslocam o sentido irredutível: à definição, a um argumento anterior, a uma unidade. Segundo a definição de estória dada no prefácio de Tutaméia "Aletria e hermenêutica", o autor pressupõe um conceito moderno de arte que tem por horizonte os efeitos de transcendência que as técnicas da poesia produzem. A ficção de Rosa leva ao extremo ou à poesia a dissolução do simbólico que o conto policial de um mestre como Edgar Allan Poe (1973) questiona, no nível do enredo, com uma ficção crítica. Na segunda leitura de um conto policial de Poe, chegamos a um argumento crítico que decifra enganos embutidos na percepção automática à qual a partilha cultural de um universo simbólico nos habitua a receber como efeito natural, insuspeito. Poe trabalha com uma técnica alegórica que duplica a narração em sentido aparente, que deve ser satisfatório em si mesmo, e sentido alusivo. A alusão a um argumento subjacente à trama completa-se na unidade de efeito. Ao duplicar o sentido em aparente e crítico, Poe usa a alegoria como crítica ao uso que o campo literário de sua época fazia da alegoria. 
No famoso ensaio que escreveu sobre Hawthorne, Poe (1973, 125-141) queixa-se de que alguns escritores contemporâneos apoiavam narrativas precárias, sem sentido suficiente nelas mesmas, na técnica da alegoria e faltavam com a verdade ao justificar narrações desfalcadas como se fossem duplos de um sentido transcendente. Poe admite a duplicação do sentido na alegoria, na imagem, desde que a narração em primeiro plano aluda a um segundo sentido também suficiente e passível de o unificarmos como argumento. $O$ segundo sentido não é metafísico, mas subterrâneo; indícios imperceptíveis emergem aqui e ali, como pistas espalhadas no conto arquitetado como uma imagem subterrânea que apenas o leitor perspicaz unifica com a imagem aparente em si mesma interessante e suficiente para leitores mais distraídos.

A ficção de Rosa dissolve a naturalização do simbólico implicada nos significados já instituídos, aqueles que obliteram a intensidade significante, com uma enunciação que explora a língua no nível extremo da poesia. A invenção começa na língua pré-Babel que, além de certa inovação sintática, inova principalmente o léxico ao combinar arcaísmos, regionalismos e neologismos (HANSEN, 2012, p.123). No prefácio "Aletria e hermenêutica", há uma anedota sobre um passageiro único no bonde que permanecia sentado debaixo de uma goteira até que despertou a perplexidade do condutor. $\mathrm{O}$ prefácio compara a paralisia do passageiro do bonde com a "gomaarábica da língua cotidiana ou círculo-de-gis-de-prender-peru" que metaforizam os usos massificados da língua empregada e divulgada pela indústria cultural (ROSA, 1979, p.4). No nível do léxico, a ficção de Rosa também dissolve a naturalização do simbólico ao parodiar provérbios, expressões, locuções como as favas contadas por Ladislau que suspendem o sentido figurado de dedução indispensável e apenas sinalizam como o capataz avalia os vaqueiros. De modo coerente com a figura discreta de Ladislau, metáfora da consideração das convenções, os períodos sintáticos de "Intruge-se" têm gramaticalidade verossímil; há apenas um período cuja gramaticalidade inusitada, poética, oferece algum obstáculo ao leitor; nela, o verbo transitivo direto mover assume a função de verbo intransitivo complementado por preposição seguida de substantivo: "Se moviam de arrebol." (ROSA, 1979, p.73). O nível da narração aponta simultaneamente para a sensatez das avaliações de Ladislau, já que o único vaqueiro suspeito acaba vitimando-se, e para o potencial de mobilidade dela. 
Um vaqueiro passou, Liocádio, agradou o cão - que latiu ou não latiu, não se ouviu. Ladislau falou, bateu na mão do outro - era por repetida vez! - de uso, de esquecido? Aquele, atentado, em trisco se rebelou, drempente, sacando faca à fura-bucho ... .

Mas Ladislau num revira-vaca, no meio do movimento, em fígado the desfechou encostadamente a parabellum de doze balas, boa arma! Espichado o ferrabruto amassou moita de mentrasto, caiu como vítima. Rigriz disse, que viu, que piscou: - "Remexam nos dobros dele, que o assassino ele era, por algum trato ou furto!"

Tal assim.

Todos se benzeram. (ROSA, 1979, p.73)

Essa reviravolta não leva a argumento nenhum, já que contra Liocádio só depõem coisas alheias ao caso do assassinato de Quio, o apelido "Piorra" e ter sido cegado de um olho antes de migrar do Norte para os gerais. Com essa reviravolta vazia, a estória "desenreda" ou dissolve a convenção narrativa monológica e realista do conto policial.

Em "Intruge-se", Rosa propõe uma alegoria da autoria que coloca a invenção em primeiro plano sem desconsiderar as convenções narrativas nas quais ela interfere. Ao parodiar o conto policial com uma alegoria que duplica o sentido, sem permitir que a segunda leitura tenha uma unidade com a primeira e sem apoiar-se em uma alusão metafísica, Rosa explora a duplicidade do signo e do sujeito. Explora a duplicidade do signo ao propor jogos significantes que colocam o leitor na posição de produtor de sentido em vez de um assimilador de conteúdos supostamente veiculados pela linguagem monológica. Explora a duplicidade do sujeito na metáfora de um outro ou de um duplo do autor, que é Ladislau, e pondera sobre as convenções narrativas por meio de jogos significantes nos quais elas deslizam, o que também dá flexibilidade e nova funcionalidade a elas como metáforas críticas da representação. O cão Eu-Meu serve como metáfora crítica da unidade do eu pressuposta pela cultura monológica que, segundo Bakhtin (1981, p.43) infiltrou-se na cultura ocidental desde o racionalismo até Dostoiévski romper com ela. A alegoria do autor, proposta no conto de Rosa, indetermina a forma com técnicas da poesia como os jogos significantes nos nomes dos personagens, a inventividade léxica e sintática. $\mathrm{O}$ autor realiza um conto moderno ao colocar as convenções narrativas em pauta por meio de metáforas críticas que sublinham o caráter inventivo da representação. 
marullu de Oliveira (aixeta

\title{
LAS HABAS DESCONTADAS POR LADISLAU EN "INTRUGE-SE."
}

RESUMEN

\begin{abstract}
Propongo una lectura del cuento "Intruge-se", que integra, entre otros, el volumen Tutaméia: terceiras estórias de João Guimarães Rosa, y consiste en una parodia de cuento policiaco, ambientada en el sertón y protagonizada por vaqueros que, conduciendo una boyada desde Saririnhém, se encuentran con un crimen. El protagonista no es un detective, sino un capataz, Ladislau, que se encarga de descubrir quién de entre los vaqueros habría apuñalado a Quio. El cuento se recusa a satisfacer cualquier expectativa de método o raciocinio deductivo, los puntos fuertes de cualquier investigador (piénsese en la teorización del género, elaborada por Edgar Allan Poe), y esa distorsión hace que el sentido de la narración se deslice del investigador hacia una alegoría del autor que hace del carácter escindido del sujeto un cuestionamiento del prestigio que ese sujeto alcanza en las sociedades modernas. La parodia del cuento policiaco en "Intruge-se" integra un conjunto de cuentos de Tutaméia que proponen una alegoría del autor. Este artículo elaborará un análisis de la parodia y de la alegoría en el cuento a partir de la teoría barthesiana de la dualidad del signo, cuya base es la afirmación freudiana del carácter escindido del sujeto, y que consiste en una recusa de la transparencia del lenguaje. La investigación no-racionalista de Ladislau performa la perspectiva del autor, que se recusa a seguir los patrones de representación realista propios del cuento policial. El autor evalúa el género cuento como una interferencia en el cuento policial y lo aproxima de la estória o de una invención, cuyo valor consiste en intervenir las convenciones narrativas para liberar la producción de sentido.
\end{abstract}

Palavras claves: Guimarães Rosa. Tutaméia. Intruge-se. Autor.

\section{REFERÊNCIAS}

AVELAR, Idelber. The logic of paradox in Guimarães Rosa's Tutaméia. Latin american literary review, v. 22, n. 43, p.6780, jan. - jun.1994. Disponível em: http://www.jstor.org/ stable/201 19672. Acesso em: 5, março, 2010. 
BAKHTIN, Mikhail. Problemas da poética de Dostoiévski. Rio de Janeiro: Forense Universitária, 1981.

BARTHES, Roland. Fragmentos de um discurso amoroso. 3.ed. Rio de Janeiro: F. Alves, 1984.

BOSI, Alfredo. Colônia, culto e cultura. In: BOSI, Alfredo. Dialética da colonização. São Paulo: Companhia das letras, 1993.

BULFINCH, Thomas. Mitologia: histórias de deuses e heróis. 34.ed. Rio de Janeiro: Ediouro, 2006.

CERVANTES, Miguel de. El colóquio de los perros. Campinas: Editora da UNICAMP, 2013.

FARIA, Ernesto (Org.). Dicionário escolar latino-português. 3.ed. Rio de Janeiro: Ministério da Educação e Cultura, Departamento Nacional de Educação, Campanha Nacional de Material de Ensino, 1962.

FREUD, Sigmund. "Oschistes e sua relação com o inconsciente". In: FREUD, Sigmund. Obras completas (vol. VIII). Rio de Janeiro: Imago Editora, 1996.

GRACIÁN, Baltasar. A arte da prudência. 2.ed. São Paulo: Martins Fontes, 2009.

HANSEN, João Adolfo. Grande sertão: veredas e o ponto de vista avaliativo do autor. Nonada, v. 10, p.57-75, 2007. Disponível em: http://seer.uniritter.edu.br/index.php/nonada/ article/view/39/13. Acesso em: 27, maio, 2009.

HOUAISS, Antônio; VILLAR, Mauro. Dicionário eletrônico Houaiss da língua portuguesa. Rio de Janeiro: Editora Objetiva, 2009. CD-ROM.

LACAN, Jacques. O Simbólico, o Imaginário e o Real [1953]. In: LACAN, Jacques. Nomes-do-Pai. Rio de Janeiro: Jorge Zahar, 2005.

MAGNE, Augusto. Dicionário etimológico da língua latina. Rio de Janeiro: MEC, 1962, vol. IV.

NOVIS, Vera. Tutaméia: engenho e arte. São Paulo: Perspectiva, 1989.

POE, Edgar Allan. Hawthorne. In: POE, Edgar Allan. Ensayos y criticas. Madrid: Alianza Editorial, 1973. p.125-141. 
ROSA, João Guimarães. Tutaméia: terceiras estórias. Rio de Janeiro: José Olympio, 1979.

ROUANET, Sergio Paulo. As razões do iluminismo. São Paulo: Companhia das Letras, 1987.

ROUDINESCO, Élisabeth; PION, Michel. Dicionário de psicanálise. Rio de Janeiro: Zahar, 1998. p. 603, 712-714.

WEIMANN, Robert. Structure and history in narrative perspective: the problem of point of view reconsidered. In: WEIMANN, Robert. Structure and society in literary history. London: The Johns Hopkins Press Ltda, 1984. p.234-266.

Recebido em: 26/06/2015

Aceito em: 25/04/2016 (reenviado) 